\title{
Asymmetric sulfoxidation of thioether catalyzed by soybean pod peroxidase to form enantiopure sulfoxide in water-in-oil microemulsions: kinetic model
}

\author{
yuanyuan Zhang ${ }^{1}$, Huiling $\mathrm{Li}^{1}$, Zhiyong Wang${ }^{1}$, Depeng $\mathrm{Li}^{1}$, and Xin Xin $\mathrm{Gao}^{1}$ \\ ${ }^{1}$ Qingdao University of Science and Technology
}

November 24, 2020

\begin{abstract}
The asymmetric sulfoxidation catalyzed by soybean pod peroxidase (SPP) in water-in-oil microemulsions were carried out with the yield of $91.56 \%$ and e.e of $96.08 \%$ at the activity of SPP of $3200 \mathrm{U} \mathrm{ml-1}$ and 50 for $5 \mathrm{~h}$. The mechanism with a two-electron reduction of SPP-I is accompanied with a single-electron transfer to SPP-I and nonenzymatic reactions, indicating that three concomitant sub-mechanisms contribute to the asymmetric oxidation involving five enzymatic and two nonenzymatic reactions, which can represent the asymmetric sulfoxidation of organic sulfides to form enantiopure sulfoxides. With $5.44 \%$ of the average relative deviation, a kinetic model fitting experimental data very well was developed. The enzymatic reactions may follow ping-pong mechanism with substrate inhibition of $\mathrm{H} 2 \mathrm{O} 2$ and product inhibition of esomeprazole, while nonenzymatic reactions, a power law. Those results indicate that SPP with a lower cost and higher thermal stability may be used as an effective substitute for Horseradish Peroxidase.
\end{abstract}

\section{Hosted file}

manuscripts-BB.pdf available at https://authorea.com/users/364771/articles/494897-asymmetricsulfoxidation-of-thioether-catalyzed-by-soybean-pod-peroxidase-to-form-enantiopuresulfoxide-in-water-in-oil-microemulsions-kinetic-model 